\title{
Can serum hyaluronic acid replace simple non-invasive indexes to predict liver fibrosis in HIV/Hepatitis C coinfected patients?
}

Salvador Resino ${ }^{1 *}$, José M Bellón ${ }^{2}$, Cristina Asensio ${ }^{3}$, Dariela Micheloud $^{1,4}$, Pilar Miralles ${ }^{5}$, Ana Vargas ${ }^{1}$, Pilar Catalán ${ }^{6}$, Juan C López ${ }^{5}$, Emilio Álvarez ${ }^{7}$, Jaime Cosin ${ }^{5}$, Raquel Lorente ${ }^{8}$, María A Muñoz-Fernández ${ }^{6,8}$, Juan Berenguer ${ }^{5}$

\begin{abstract}
Background: Hyaluronic acid (HA) serum levels correlate with the histological stages of liver fibrosis in hepatitis $C$ virus (HCV) monoinfected patients, and $\mathrm{HA}$ alone has shown very good diagnostic accuracy as a non-invasive assessment of fibrosis and cirrhosis. The aim of this study was to evaluate serum HA levels as a simple non-invasive diagnostic test to predict hepatic fibrosis in HIV/HCV-coinfected patients and to compare its diagnostic performance with other previously published simple non-invasive indexes consisting of routine parameters (HGM-1, HGM-2, Forns, APRI, and FIB-4).

Methods: We carried out a cross-sectional study on 201 patients who all underwent liver biopsies and had not previously received interferon therapy. Liver fibrosis was determined via METAVIR score. The diagnostic accuracy of HA was assessed by area under the receiver operating characteristic curves (AUROCs).

Results: The distribution of liver fibrosis in our cohort was $58.2 \%$ with significant fibrosis ( $F \geq 2), 31.8 \%$ with advanced fibrosis ( $F \geq 3$ ), and $11.4 \%$ with cirrhosis (F4). Values for the AUROC of HA levels corresponding to significant fibrosis $(F \geq 2)$, advanced fibrosis $(F \geq 3$ ) and cirrhosis ( $F 4$ ) were $0.676,0.772$, and 0.863 , respectively. The AUROC values for HA were similar to those for HGM-1, HGM-2, FIB-4, APRI, and Forns indexes. The best diagnostic accuracy of HA was found for the diagnosis of cirrhosis (F4): the value of HA at the low cut-off $(1182 \mathrm{ng} / \mathrm{mL}$ ) excluded cirrhosis (F4) with a negative predictive value of $99 \%$ and at the high cut-off ( $2400 \mathrm{ng} / \mathrm{mL}$ ) confirmed cirrhosis (F4) with a positive predictive value of 55\%. By utilizing these low and high cut-off points for cirrhosis, biopsies could have theoretically been avoided in $52.2 \%$ (111/201) of the patients.

Conclusions: The diagnostic accuracy of serum HA levels increases gradually with the hepatic fibrosis stage. However, HA is better than other simple non-invasive indexes using parameters easily available in routine clinical practice only for the diagnosing of cirrhosis.
\end{abstract}

\section{Background}

Human immunodeficiency virus (HIV) infection influences the natural evolution of chronic hepatitis $\mathrm{C}$ $(\mathrm{CHC})$ infection by accelerating fibrosis progression and increasing the rate of cirrhosis and end-stage liver disease in $\mathrm{HIV} /$ hepatitis $\mathrm{C}$ virus $(\mathrm{HCV})$ coinfected patients $[1,2]$. Despite a decline in morbidity/mortality from opportunistic infections since the introduction of highly

\footnotetext{
* Correspondence: sresino@isciii.es

'Laboratory of Molecular Epidemiology of Infectious Diseases, National Centre of Microbiology, Instituto de Salud Carlos III, Majadahonda, Madrid, Spain

Full list of author information is available at the end of the article
}

active antiretroviral therapy (HAART), end-stage liver disease continues to be a frequent cause of hospitalization and death in patients coinfected with HIV and $\mathrm{HCV}[3,4]$.

Staging liver fibrosis is considered to be an essential part in the management of patients with $\mathrm{CHC}$, because it provides prognostic information and, in many cases, assists in therapeutic decisions. For many years, the diagnosis and quantification of fibrosis have relied on liver biopsies, a procedure with several drawbacks (bleeding in the liver and around the site of the procedure, pain around the biopsy area, infection, damage to

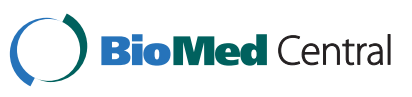

() 2010 Resino et al; licensee BioMed Central Ltd. This is an Open Access article distributed under the terms of the Creative Commons Attribution License (http://creativecommons.org/licenses/by/2.0), which permits unrestricted use, distribution, and reproduction in any medium, provided the original work is properly cited. 
liver tissue, etc.) [5]. Currently, there are several noninvasive diagnostic methods for determining liver fibrosis that are being validated, such as blood markers and imaging methods [6].

One of these blood markers is hyaluronic acid (HA), an essential component of the extracellular matrix in virtually every tissue of the body. In the liver, HA is mostly synthesized by hepatic stellate cells and degraded by sinusoidal endothelial cells [7]. HA serum levels have been found to correlate with the histological stages of liver fibrosis in HCV monoinfected patients [8], and HA alone has shown very good diagnostic accuracy for the non-invasive assessment of fibrosis and cirrhosis $[9,10]$.

The purpose of our study was to evaluate serum HA levels as a simple non-invasive diagnostic test to predict hepatic fibrosis in HIV/HCV-coinfected patients and to compare its diagnostic performance with other previously published simple non-invasive indexes consisting of routine parameters.

\section{Methods}

\section{Patients}

We carried out a retrospective cross-sectional study of all patients with documented HIV/HCV coinfection who underwent a liver biopsy between May 2000 and May 2007 at the HIV outpatient clinic of the Hospital Gregorio Marañón in Madrid (Spain).

Liver biopsies were performed on patients who were potential candidates for interferon plus ribavirin therapy and had no prior HCV therapy. The inclusion criteria were: availability of a frozen serum sample collected on the day of liver biopsy; no clinical evidence of hepatic decompensation; detectable HCV RNA by polymerase chain reaction; negative for hepatitis $B$ surface antigen; CD4+ lymphocyte count higher than 200 cells $/ \mu \mathrm{L}$; antiretroviral therapy or no need for antiretroviral therapy; and absence of diabetes, active opportunistic infections, or active drug or alcohol addiction.

From our cohort of 361 patients with liver biopsy data, only 201 could be included because they had had a serum sample collected and frozen. The group of excluded patients had significant differences in the numbers of patients on antiretroviral therapy with NNRTI (included (104/201 patients (51.7\%)) vs. excluded (57/ 160 patients $(36.3 \%)), \mathrm{p}<0.05)$, advanced fibrosis diagnosis (included $(41 / 201$ patients $(20.4 \%))$ vs. excluded (18/160 patients $(11.3 \%)), \mathrm{p}<0.05)$, undetectable plasma HIV viral load (included (156/201 patients $(77.6 \%)$ ) vs. excluded (90/160 patients $(56.3 \%)), \mathrm{p}<0.05)$, plasma HCV RNA $>850.000$ copies/ml (included (125/201 patients $(75.8 \%))$ vs. excluded (95/160 patients $(63.3 \%))$, $\mathrm{p}<0.05)$, and plasma AST levels (included (57 IU/L) vs. excluded (65.5 IU/L), $\mathrm{p}<0.05)$.
All work was conducted in accordance with the Declaration of Helsinki. All patients gave their written informed consent for the liver biopsies, and the Institutional Ethics Committee approved the study.

\section{Clinical and Laboratory data}

Immediately prior to the liver biopsy, a fasting blood sample was taken from the patient to analyze complete blood counts, liver panel, basic metabolic panel, coagulation tests, HIV viral load, and $\mathrm{CD}^{+}$counts. The duration of HCV infection for all patients with a history of intravenous drug use was estimated from the first year needles were shared, and the others patients were considered to have an "unknown" HCV infection duration. Also, a serum sample was immediately frozen $\left(-70^{\circ} \mathrm{C}\right)$ and stored for further assays.

HIV and HCV infection were documented in all patients by enzyme-linked immunosorbent assay (ELISA) and polymerase chain reaction (PCR). The HCV viral load was measured by PCR (Cobas Amplicor HCV Monitor Test, Branchburg, NJ, USA). HCV genotype was determined by hybridization of biotin-labeled PCR products to oligonucleotide probes bound to nitrocellulose membrane strips (INNO-LiPA HCV II, Innogenetics, Ghent, Belgium). HA was tested in serum samples by a commercially available quantitative ELISA (HA-ELISA; Echelon Biosciences Inc., Salt Lake City, UT, USA). Concentrations were assayed in duplicate.

For purposes of comparison with HA, we evaluated 5 reported simple models consisting of routine parameters to predict liver fibrosis: Forns [11], APRI [12], FIB-4 [13], HGM-1 and HGM-2 indexes [14] (Table 1).

\section{Liver biopsy and histology}

Liver biopsies were performed on an outpatient basis following the recommendations of the Patient Care Committee of the American Gastroenterological Association [15]. All liver biopsies were performed by the same physicians (J.B. and P.M.) with a suction needle (HISTO-CUT 16G, Sterylab Srl. Milano, Italy). Ultrasound was routinely used to determine the percutaneous biopsy site. We did not systematically record the size of liver biopsy specimens, however, during the study period, only 5 out of 297 biopsies yielded insufficient liver tissue for pathological diagnosis.

The liver tissue sections were fixed in fomalin, embedded in paraffin and stained by hematoxylin-eosin, Mason's trichrome, and Perls' iron. The samples were evaluated by a single pathologist (E.A.). Liver fibrosis was estimated prospectively following the criteria established by the METAVIR Cooperative Study Group [16]. Fibrosis was scored as follows: F0, no fibrosis; F1, portal fibrosis; F2 periportal fibrosis or rare portal-portal septa; F3, fibrous septa with 
Table 1 Simple non-invasive models for liver fibrosis consisting of routine parameters

\begin{tabular}{|c|c|c|}
\hline Index & Mathematical formula & Reference \\
\hline Forns & $\begin{aligned} 7.811-3.131 * \operatorname{LN}\left(\text { Platelet count }\left(10^{9} / \mathrm{L}\right)+0.781 * \operatorname{LN}(\mathrm{GGT})+3.467 * \mathrm{LN} \text { (Age) }\right. \\
-0.014^{*} \text { cholesterol }\end{aligned}$ & [11] \\
\hline \multirow[t]{2}{*}{ APRI } & $100 *\left(\frac{A S T(I U / L)}{40}\right)$ & \multirow{2}{*}[12]{} \\
\hline & $\overline{\text { Platelet count }\left(10^{9} / L\right)}$ & \\
\hline \multirow{2}{*}{ FIB-4 } & Age $(\text { years })^{*} A S T(I U / L)$ & \multirow{2}{*}{ [13] } \\
\hline & Platelet count $\left(10^{9} / L\right)^{*} \sqrt{A L T(I U / L)}$ & \\
\hline \multirow[b]{2}{*}{ HGM-1 } & 1 & \multirow[b]{2}{*}{ [14] } \\
\hline & $1+\mathrm{e}^{\left(1.971+0.012^{*} \text { Platelet count }\left(10^{9} / L\right)-0.026^{*} \text { AST }(\mathrm{IU} / \mathrm{L}) \quad 0.033^{*} \text { glucose }(\mathrm{mg} / \mathrm{dL})\right)}$ & \\
\hline \multirow{2}{*}{ HGM-2 } & 1 & \multirow{2}{*}{ [14] } \\
\hline & $1+\mathrm{e}^{\left(6.175-0.010 \operatorname{ALP}(I U / L)-4.8^{*} \mathrm{INR}+0.010^{*} \text { Platelet count }\left(10^{9} / L\right)-0.007^{*} \operatorname{AST}(I U / L)\right)}$ & \\
\hline
\end{tabular}

Abreviations: LN, logarithm neperian; GGT, gamma glutamyl transpeptidase; AST, aspartate aminotransferase; ALT, alanine aminotransferase; INR, international normalized ratio; ALP, alkaline phosphatase.

architectural distortion but with no obvious cirrhosis (bridging fibrosis); and F4, definite cirrhosis. The researchers in charge of evaluating the biopsies, interpreting the clinical data, or calculating and analyzing the reference standard had no prior knowledge of results.

\section{Statistical analysis}

Overall, results are presented as medians $\left(25^{\text {th }}\right.$ percentile, $75^{\text {th }}$ percentile) for continuous variables and as frequencies and percentages for categorical data. Comparisons between HA levels and fibrosis stage were analyzed using the Mann-Whitney U-test. All tests were two-tailed with a p-value $\leq 0.05$ considered to be significant. Statistical analysis was performed using SPSS 16.0 software (SPSS INC, Chicago, IL, USA) and STATA 9.1 (College Station, TX, USA).

We evaluated the diagnostic performance of all indexes using the receiver operating characteristic (ROC) curve constructed to study the absence and presence of significant fibrosis $(\mathrm{F} \geq 2)$, advanced fibrosis $(\mathrm{F} \geq 3)$, and cirrhosis (F4), and comparing the area under these ROC curves (AUC-ROCs) [17,18] with a nonparametric ROC analyses adjusted by Sidak's method for the effect of multiple comparisons.

For each fibrosis stage, we chose a low cut-off at 95\% sensitivity (Se) used to predict the absence of the disease and a high cut-off at $95 \%$ specificity (Sp) used to predict the presence of the disease. Additional analyses of cutoffs that optimized both Se and Sp were also performed. The "optimal" cut-off was defined as the maximum of $(\mathrm{Se}+\mathrm{Sp})$. We calculated the Se, Sp, positive predictive value (PPV) and negative predictive value (NPV) for each cut-off point. We also calculated the diagnostic odds ratio (DOR) which expresses the strength of the association between test result and disease: it is the ratio of the odds of a positive result in a person with the target condition compared to a person without the condition [19]. A DOR of 1 suggests the test providing no diagnostic evidence. Moreover, we also calculated the likelihood ratios (LR) which describe how many times a person with the target condition is more likely to have a particular test result than a person without that condition. LRs contribute to change the probability that a target condition is present after the test has been made. Binary tests have two LRs, positive and negative (LR+, LR-). A LR of 1 indicates no diagnostic value.

Finally, we calculated the percentage of patients in whom the results of the HA could have avoided the biopsy. For this purpose, we constructed three new $2 \times$ 2 contingency tables combining the two cut-off points for comparing the results that were lower than the low cut-off (discarding significant fibrosis) and the results that were higher than the high cut-off point (for significant fibrosis, for advanced fibrosis, and for cirrhosis, respectively) with the corresponding biopsy results. From each table, patients correctly classified (true positive $(\mathrm{TP})+$ true negatives $(\mathrm{TN})$ ) by the test would not have needed the biopsy procedure.

\section{Results}

Patients

General characteristics of the $201 \mathrm{HIV} / \mathrm{HCV}$-coinfected patients at the time of liver biopsy are shown in Table 2. Overall, $94.5 \%$ were on HAART: $23.4 \%$ with protease inhibitor based therapy, $51.7 \%$ with non-nucleoside analogue based therapy, $12.4 \%$ with 3 nucleoside analogue based therapy, and $7.5 \%$ with other drugs. The distribution of liver fibrosis in our cohort was $58.2 \%$ with significant fibrosis $(\mathrm{F} \geq 2), 31.8 \%$ with advanced fibrosis $(\mathrm{F} \geq 3)$, and $11.4 \%$ with cirrhosis (F4). 
Table 2 Characteristics of the 201 HIV/HCV-coinfected patients, who underwent liver biopsies

\begin{tabular}{|c|c|}
\hline Characteristic & Values \\
\hline No. HIV-1 patients * & 201 \\
\hline Sex (male) * & $152(75.6)$ \\
\hline Age (years) $^{\dagger}$ & $39.4(36.8 ; 43.3)$ \\
\hline HIV acquired by IVDU * & $180(89.6)$ \\
\hline Prior AIDS * & $62(30.8)$ \\
\hline Years since HCV infection ${ }^{\dagger, \neq}$ & $21.3(17.7 ; 24.3)$ \\
\hline High alcohol intake ${ }^{*}, \S$ & $28(14)$ \\
\hline \multicolumn{2}{|l|}{ Antiretroviral therapy } \\
\hline Non treated * & $10(5)$ \\
\hline PI-based * & $47(23.4)$ \\
\hline NNRTI-based * & $104(51.7)$ \\
\hline 3 NRTI-based * & $25(12.4)$ \\
\hline Other * & $15(7.5)$ \\
\hline Months on HAART $(n=190)^{\dagger}$ & $50.2(34.9 ; 65.7)$ \\
\hline \multicolumn{2}{|l|}{ Stage of liver fibrosis * } \\
\hline Fo & $16(8)$ \\
\hline F1 & $68(33.8)$ \\
\hline F2 & $53(26.4)$ \\
\hline F3 & $41(20.4)$ \\
\hline F4 & $23(11.4)$ \\
\hline Fibrosis progression index ${ }^{\dagger}$ & $0.08(0.05 ; 0.15)$ \\
\hline \multicolumn{2}{|l|}{ HIV markers } \\
\hline Nadir CD4+ T-cells ${ }^{\dagger}$ & $210(103 ; 324)$ \\
\hline Baseline CD4+ T-cells $/ \mu \mathrm{L}^{\dagger}$ & $490(373 ; 660)$ \\
\hline HIV-RNA $<50 \mathrm{cp} / \mathrm{mL}^{*}$ & $156(77.6)$ \\
\hline Log10 VL copies/mL $(n=45)$ & $3.23(2.71 ; 3.98)$ \\
\hline \multicolumn{2}{|l|}{ HCV markers * } \\
\hline \multicolumn{2}{|l|}{ HCV genotype } \\
\hline 1 or 4 & $153(77.3)$ \\
\hline 3 & $45(22.7)$ \\
\hline HCV-RNA >850,000 cp/ml & $125(75.8)$ \\
\hline \multicolumn{2}{|l|}{ Hematologic parameters $^{\dagger}$} \\
\hline Platelet count $\left(\times 10^{9} / \mathrm{L}\right)$ & $177(140 ; 221)$ \\
\hline Fibrinogen (mg/dL) & $259(228 ; 305)$ \\
\hline INR & $1(1 ; 1.02)$ \\
\hline \multicolumn{2}{|l|}{ Biochemical parameters $^{+}$} \\
\hline ALP (IU/L) & $124(81 ; 196)$ \\
\hline AST (IU/L) & $57(37.5 ; 85)$ \\
\hline GGT (IU/L) & $113(58 ; 208)$ \\
\hline ALT (IU/L) & $77(49 ; 117)$ \\
\hline AST/ALT & $0.75(0.6 ; 0.97)$ \\
\hline
\end{tabular}

${ }^{*}$ Absolute number (percentage). ${ }^{+}$Median $\left(25^{\text {th }}\right.$ percentile; $75^{\text {th }}$ percentile). $\neq$ The duration of $\mathrm{HCV}$ infection for patients with a history of intravenous drug use (IVDU) was calculated starting from the first year needles were shared. Duration of HCV infection was considered to be unknown for subjects infected through sexual contact. §Patients were questioned in relation to alcohol consumption. The consumption of $>50 \mathrm{gr}$. of alcohol per day for $\geq 12$ months was considered as a high intake.

Abbreviations: HCV, Hepatitis C virus; HIV-1, Human immunodeficiency virus type 1; IVDU, intravenous drug users; HAART, highly active antiretroviral therapy; NRTI, nucleoside analogue HIV reverse transcriptase inhibitor; NNRTI, non-nucleoside analogue HIV reverse transcriptase inhibitor; Pl, protease inhibitor; HIV-RNA, HIV plasma viral load; HCV-RNA, HCV plasma viral load; INR, international normalized ratio; ALP, alkaline phosphatase; AST, aspartate aminotransferase; GGT, gamma glutamyl transpeptidase; ALT, alanine aminotransferase. 


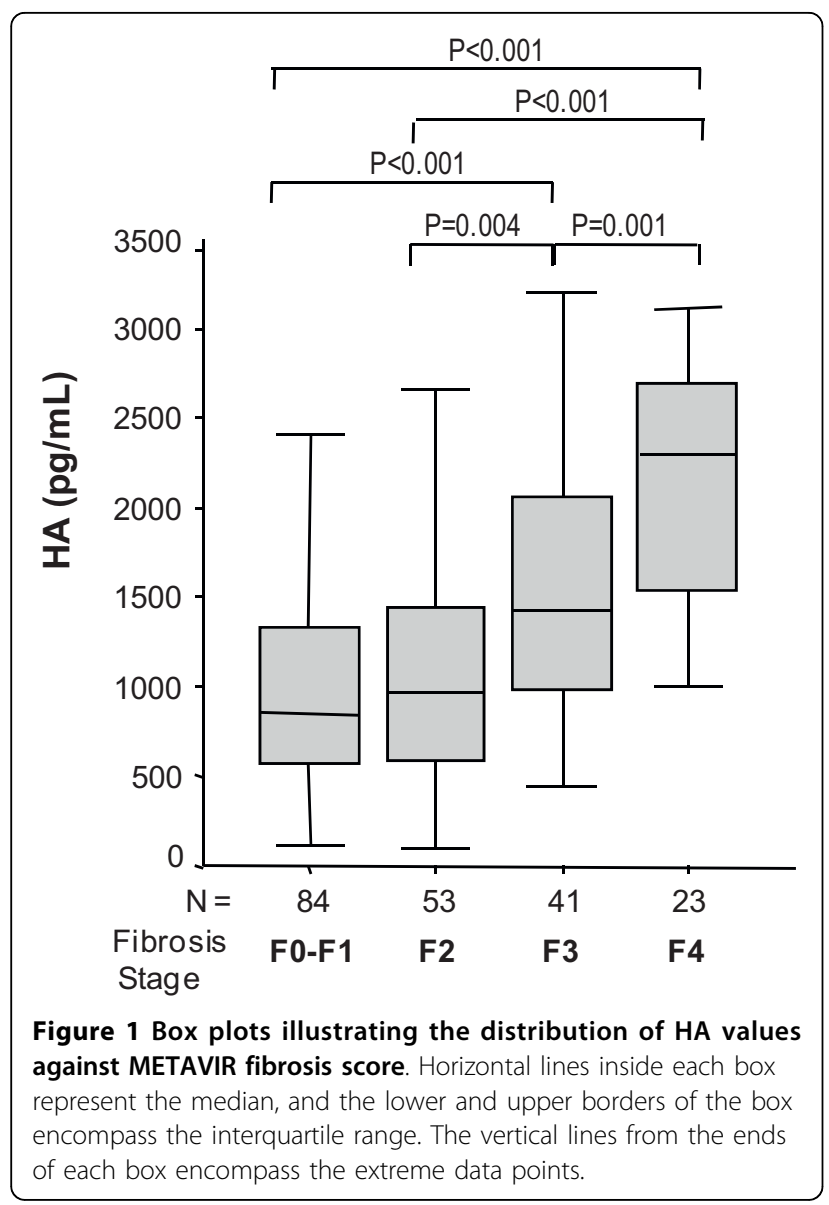

\section{Diagnostic performance}

HA levels increased significantly with the stage of hepatic fibrosis (Figure 1A). The highest values of HA were found in cirrhotic patients. The AUC-ROC values of the HA for significant fibrosis $(\mathrm{F} \geq 2)$, advanced fibrosis $(\mathrm{F} \geq 3)$ and cirrhosis (F4) were similar to those of the Forns, APRI, FIB-4, HGM-1 and HGM-2 indexes (Figure 2B).

\section{Evaluation of cut-off points}

For significant fibrosis $(\mathrm{F} \geq 2)$, using a low cut-off of $430 \mathrm{ng} / \mathrm{mL} \mathrm{HA}, 13$ of 84 (15.5\%) patients with $\mathrm{F}<2$ were correctly identified, and only 6 of 117 (5.1\%) patients with $\mathrm{F} \geq 2$ were misclassified (61.0\% PPV and $68.4 \%$ NPV). With a high cut-off of $1800 \mathrm{ng} / \mathrm{mL}, 36$ of 117 (30.8\%) patients with $\mathrm{F} \geq 2$ were correctly identified, and only 4 of $84(4.8 \%)$ of patients with $\mathrm{F}<2$ were misclassified (90\% PPV and 49.7\% NPV) (Table 3). Considering these low and high cut-off points, biopsies could have been avoided in $24.4 \%(49 / 201)$ of patients by using HA instead. When we applied an optimal cut-off of $1250 \mathrm{ng} / \mathrm{mL}, 128$ patients were correctly identified (67 patients were TP and 61 patients were TN), and 83

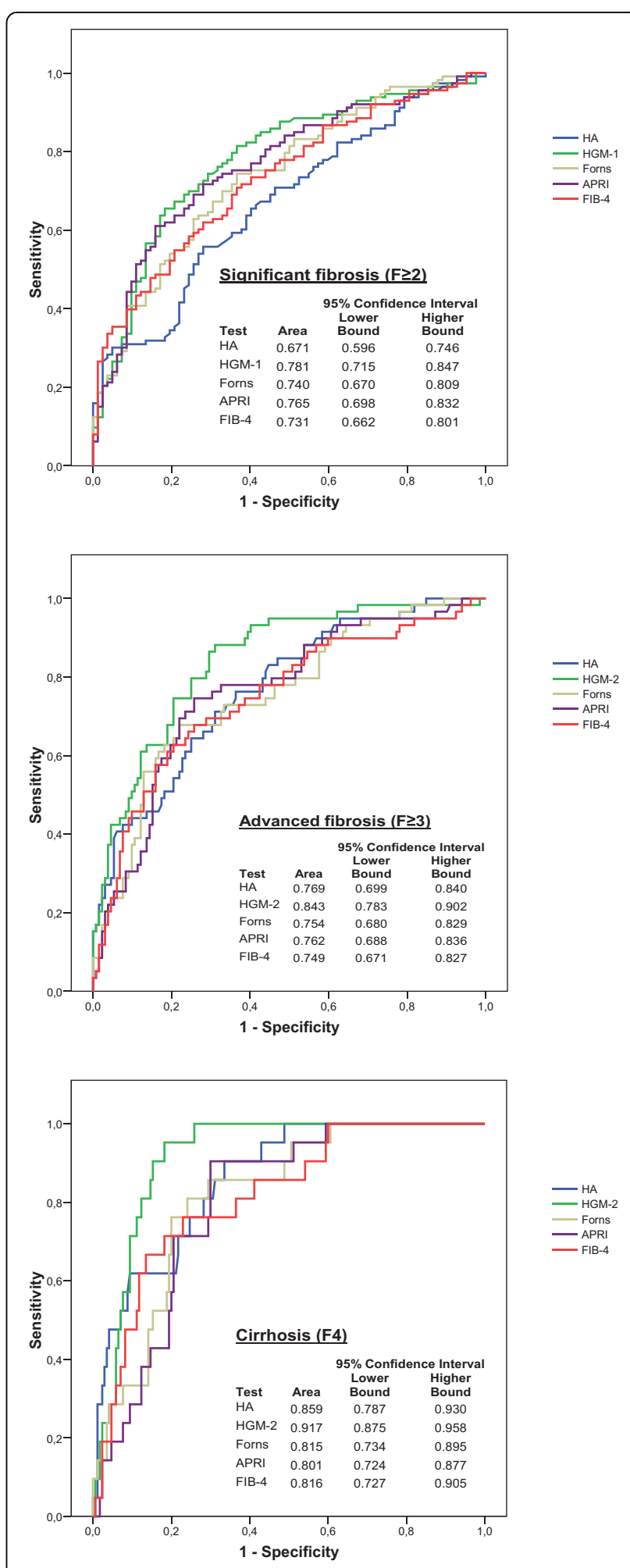

Figure 2 Area under the receiver operating characteristic (AUCROCs) curves of HA, HGM-1, HGM-2, FIB-4, APRI and Forns indexes for significant fibrosis $(F \geq 2)$, advanced fibrosis $(F \geq 3)$ and cirrhosis (F4). 
Table 3 Diagnostic accuracy of hyaluronic acid (HA) measurement for significant fibrosis ( $\mathrm{F} \geq 2$ ), advanced fibrosis ( $\geq 3$ ) and cirrhosis (F4) in our cohort

\begin{tabular}{|c|c|c|c|c|c|c|c|c|c|c|c|}
\hline$\overline{\text { Cut-off }}$ & TP & FP & TN & $\mathrm{FN}$ & $\begin{array}{c}{ }^{(*)} \mathrm{Se} \\
(95 \% \mathrm{Cl})\end{array}$ & $\begin{array}{c}{ }^{(*)} \mathrm{Sp} \\
(95 \% \mathrm{Cl})\end{array}$ & $\begin{array}{l}{ }^{(*)} \mathrm{PPV} \\
(95 \% \mathrm{Cl})\end{array}$ & $\begin{array}{l}{ }^{(*)} \mathrm{NPV} \\
(95 \% \mathrm{Cl})\end{array}$ & $\begin{array}{c}\mathrm{LR}+ \\
(95 \% \mathrm{Cl})\end{array}$ & $\begin{array}{c}\text { LR- } \\
(95 \% \mathrm{Cl})\end{array}$ & $\begin{array}{c}\text { DOR } \\
(95 \% \mathrm{Cl})\end{array}$ \\
\hline \multicolumn{12}{|c|}{ Significant fibrosis $(F \geq 2)$} \\
\hline $30(r$ & 111 & 71 & 13 & 6 & $\begin{array}{c}94.9 \\
(90.4-99.3)\end{array}$ & $\begin{array}{c}15.5 \\
(7.1-23.8)\end{array}$ & $\begin{array}{c}61.0 \\
(53.6-68.7)\end{array}$ & $\begin{array}{c}68.4 \\
(44.9-91.9)\end{array}$ & $\begin{array}{c}1.12 \\
(1.01-1.24)\end{array}$ & $\begin{array}{c}0.33 \\
(0.14-0.78)\end{array}$ & $\begin{array}{c}3.39 \\
(1.23-9.32)\end{array}$ \\
\hline $1250(\mathrm{ng} / \mathrm{mL})$ & 67 & 23 & 61 & 50 & $\begin{array}{c}57.3 \\
(47.9-66.7)\end{array}$ & $\begin{array}{c}72.6 \\
(62.5-82.7)\end{array}$ & $\begin{array}{c}74.4 \\
(64.9-84.0)\end{array}$ & $\begin{array}{c}55.0 \\
(45.2-64.7)\end{array}$ & $\begin{array}{c}2.09 \\
(1.43-3.06)\end{array}$ & $\begin{array}{c}0.59 \\
(0.46-0.75)\end{array}$ & $\begin{array}{c}3.55 \\
(1.9-6.5)\end{array}$ \\
\hline 1800 & 36 & 4 & 80 & 81 & $\begin{array}{c}30.8 \\
(21.9-39.6)\end{array}$ & $\begin{array}{c}95.2 \\
(90.1-100)\end{array}$ & $\begin{array}{c}90.0 \\
(79.5-100)\end{array}$ & $\begin{array}{c}49.7 \\
(41.7-57.7)\end{array}$ & $\begin{array}{c}6.46 \\
(2.39-17.46)\end{array}$ & $\begin{array}{c}0.73 \\
(0.63-0.84)\end{array}$ & $\begin{array}{c}8.89 \\
(3.02-26.13)\end{array}$ \\
\hline \multicolumn{12}{|c|}{ Advanced fibrosis ( $F \geq 3$ ) } \\
\hline $87(\mathrm{ng} / \mathrm{mL})$ & 61 & 88 & 49 & 3 & $\begin{array}{c}95.3 \\
(89.3-100)\end{array}$ & $\begin{array}{c}35.8 \\
(27.4-44.2)\end{array}$ & $\begin{array}{c}40.9 \\
(32.7-49.2)\end{array}$ & $\begin{array}{c}94.2 \\
(86.9-100)\end{array}$ & $\begin{array}{c}1.48 \\
(1.29-1.70)\end{array}$ & $\begin{array}{c}0.13 \\
(0.04-0.40)\end{array}$ & $\begin{array}{c}11.32 \\
(3.37-37.99)\end{array}$ \\
\hline $1250(\mathrm{ng} / \mathrm{mL})$ & 47 & 43 & 94 & 17 & $\begin{array}{c}73.4 \\
(61.8-85.0)\end{array}$ & $\begin{array}{c}68.6 \\
(60.5-76.7)\end{array}$ & $\begin{array}{c}52.2 \\
(41.3-63.1)\end{array}$ & $\begin{array}{c}84.7 \\
(77.5-91.8)\end{array}$ & $\begin{array}{c}2.34 \\
(1.75-3.12)\end{array}$ & $\begin{array}{c}0.39 \\
(0.25-0.6)\end{array}$ & $\begin{array}{c}6.04 \\
(3.1-11.7)\end{array}$ \\
\hline /mL) & 18 & 7 & 130 & 46 & $\begin{array}{c}28.1 \\
(16.3-39.9)\end{array}$ & $\begin{array}{c}94.9 \\
(90.8-98.9)\end{array}$ & $\begin{array}{c}72.0 \\
(52.4-91.6)\end{array}$ & $\begin{array}{c}73.9 \\
(67.1-80.6)\end{array}$ & $\begin{array}{c}5.50 \\
(2.42-12.51)\end{array}$ & $\begin{array}{c}0.76 \\
(0.63-0.91)\end{array}$ & $\begin{array}{c}7.27 \\
(2.85-18.52)\end{array}$ \\
\hline \multicolumn{12}{|l|}{ Cirrhosis (F4) } \\
\hline $1182(\mathrm{ng} / \mathrm{mL})$ & 22 & 78 & 100 & 1 & $\begin{array}{c}95.7 \\
(85.1-100)\end{array}$ & $\begin{array}{c}56.2 \\
(48.6-63.7)\end{array}$ & $\begin{array}{c}22.0 \\
(13.4-30.6)\end{array}$ & $\begin{array}{c}99.0 \\
(96.6-100)\end{array}$ & $\begin{array}{c}2.18 \\
(1.81-2.63)\end{array}$ & $\begin{array}{c}0.08 \\
(0.01-0.53)\end{array}$ & $\begin{array}{c}28.21 \\
(3.72-213.86)\end{array}$ \\
\hline 1320 (ng/mL) & 21 & 63 & 115 & 2 & $\begin{array}{c}91.3 \\
(77.6-100)\end{array}$ & $\begin{array}{c}64.6 \\
(57.3-71.9)\end{array}$ & $\begin{array}{c}25.0 \\
(17.1-34.9)\end{array}$ & $\begin{array}{c}98.3 \\
(95.5-100)\end{array}$ & $\begin{array}{c}2.58 \\
(2.04-3.26)\end{array}$ & $\begin{array}{c}0.13 \\
(0.04-0.51)\end{array}$ & $\begin{array}{c}19.17 \\
(4.4-84.4)\end{array}$ \\
\hline 40 & 11 & 9 & 169 & 12 & $\begin{array}{c}47.8 \\
(25.2-70.4)\end{array}$ & $\begin{array}{c}94.9 \\
(91.4-98.4)\end{array}$ & $\begin{array}{c}55.0 \\
(30.7-79.3)\end{array}$ & $\begin{array}{c}93.4 \\
(89.5-97.3)\end{array}$ & $\begin{array}{c}9.46 \\
(4.40-20.36)\end{array}$ & $\begin{array}{c}0.55 \\
(0.36-0.82)\end{array}$ & $\begin{array}{c}17.21 \\
(5.98-49.57)\end{array}$ \\
\hline
\end{tabular}

For each fibrosis stage, we chose a low cut-off at 95\% sensitivity (Se) used to predict the absence of the disease and a high cut-off at $95 \%$ specificity (Sp) used to predict the presence of the disease.

Abbreviations: TP, true positive cases (correct diagnosis); FP, false positive cases (over-diagnosis); TN, true negative cases (correct diagnosis); FN, false negative cases (missed cases); Se, sensitivity; Sp, specificity; PPV, positive predictive value; NPV, negative predictive value; LR, likelihood ratio; DOR, diagnostic odds ratio; $(*)$ : values as percentage $(\%)$.

patients were misclassified (23 patients were false positive (FP) and 50 patients were false negatives (FN)) (Table 3). The diagnostic accuracy estimates, the PPV, NPV, LR-, LR+ and DOR, all of them were not good enough.

For advanced fibrosis $(\mathrm{F} \geq 3)$, using a low cut-off of 687 $\mathrm{ng} / \mathrm{mL}, 49$ of 137 (35.8\%) patients with $\mathrm{F}<3$ were correctly identified, and only 3 of 64 (4.8\%) patients with $\mathrm{F} \geq 3$ were misclassified (40.9\% PPV and 94.2\% NPV). With a high cut-off of $2290 \mathrm{ng} / \mathrm{mL}, 18$ of 64 (28.1\%) patients with $\mathrm{F} \geq 3$ were correctly identified and only 7 of 137 (5.1\%) patients with $\mathrm{F}<3$ were misclassified $(72 \%$ PPV and 73.9\% NPV) (Table 3). Considering these low and high cut-off points, biopsies could have been avoided in $33.3 \%(67 / 201)$ of patients by using HA instead. When we applied an optimal cut-off of 1250 $\mathrm{ng} / \mathrm{mL}, 141$ patients were correctly identified (47 patients were TP and 94 patients were TN), and 60 patients were misclassified (43 patients were FP and 17 patients were FN) (Table 3). The NPV value almost reached $85 \%$ but the PPV, LR-, LR+ and DOR were not good enough.

For cirrhosis (F4), using a low cut-off of $1182 \mathrm{ng} /$ $\mathrm{mL}, 100$ of 178 (56.2\%) patients with $\mathrm{F}<4$ were correctly identified, and only 1 of 23 (4.3\%) patients with
F4 was misclassified (22.2\% PPV and 99\% NPV). With a high cut-off of $2400 \mathrm{ng} / \mathrm{mL}, 11$ of $23(47.8 \%)$ patients with F4 were correctly identified, and only 9 of $178(5.1 \%)$ patients with $\mathrm{F}<4$ were misclassified (55\% PPV and 93.4\% NPV) (Table 3). Considering these low and high cut-off points, biopsies could have been avoided in $52.2 \%(111 / 201)$ of patients by using HA instead. When we applied an optimal cut-off of $1320 \mathrm{ng} / \mathrm{mL}, 136$ patients were correctly identified (21 patients were TP and 115 patients were $\mathrm{TN}$ ), and 65 patients were misclassified (63 patients were FP and 2 patients were FN) (Table 3). Using HA to predict cirrhosis, the NPV, LR-, and DOR value had good enough values.

\section{Discussion}

In this study, we found that serum HA levels were positively correlated with the stages of liver fibrosis. Moreover, the AUC-ROC increased with the stage of fibrosis with the highest value found for cirrhosis. HA was moderately accurate at the diagnosis of $\mathrm{F} \geq 2$ (AUC-ROC of 0.676), while it seemed to be a very useful method for the detection of cirrhosis (AUC-ROC of 0.863). Many fibrosis experts would consider non-invasive tests for fibrosis with an AUC-ROC value of 0.85-0.90 to be as 
good as liver biopsies for staging fibrosis [20]. Some authors have argued that some non-invasive markers of fibrosis might be even more accurate than biopsies and that most of the significantly discordant results between biopsies and non-invasive tests may be due to the method of obtaining biopsies that does not demonstrate the actual liver fibrosis state (sampling error when performing the biopsies) [21].

HA has been described as a component of several fibrosis indexes or as a single parameter for the noninvasive assessment of fibrosis/cirrhosis in HIV/HCVcoinfected patients [22-25]. In HIV/HCV-coinfected patients, there are few published studies with HA alone, and they are limited by their small sample sizes [25] or were designed to only evaluate significant fibrosis [23].

The diagnostic performance of HA was similar to the Forns, APRI, FIB-4, HGM-1 and HGM-2 indexes for our $\mathrm{HIV} / \mathrm{HCV}$-coinfected patients. We also found that the AUC-ROC of HA was similar to the AUC-ROC values of APRI, FIB-4, and Forns indexes obtained by other authors in HIV/HCV-coinfected patients [26-30] but lower than the AUC-ROC values of APRI, FIB-4, and Forns found in several studies carried out on HCVmonoinfected patients $[11,12,31]$. In summary, according to this study the performance of HA is not better than several biomarkers using parameters easily available in routine clinical practice in $\mathrm{HIV} / \mathrm{HCV}$-coinfected patients.

The clinical utility of HA in our study was low except for cirrhosis as the AUC-ROC for cirrhosis was the only one that was higher than 0.850. Also, the NPV was 99\%, which could be acceptable for excluding cirrhosis. However, the PPV was only 55\%, which is unacceptable for the diagnosis of cirrhosis; although this value can be explained due to the low number of cirrhotic patients in our cohort. Naturally, ruling out cirrhosis is of less importance in the management of patients than confirming such a diagnosis. According to all the available data, the practical interest of the isolated use of HA for assessing liver fibrosis in $\mathrm{HIV} / \mathrm{HCV}$-coinfected patients in clinical practice seems to be rather low.

The advantage of HA over the other simple non-invasive indexes (APRI, FIB-4, HGM-1 and HGM-2) is that these indexes could be affected by some factors associated with HIV infection such as biochemical and haematological abnormalities and antiretroviral therapy [32-34], which can lead to an increase in transaminases or cholesterol in the blood [32-34]. HAART has increased the incidence of significant metabolic disturbances. These metabolic disturbances produce clinical manifestations which have an impact on the future health of the HIV-infected patient, including hyperlipidaemia, lipodystrophy, metabolic syndrome, cardiovascular disease and type 2 diabetes [35,36]. Moreover, hepatotoxicity is a serious complication in patients taking HAART and coinfection with HCV increases the risk of liver toxicity while taking antiretroviral therapy [32]. HCV coinfection is associated with a 2 to 10 -fold chance of developing elevated transaminase levels during HAART [33]. The evidence of severe hepatic dysfunction (coagulopathy or elevation of ammonia levels) is suggestive of severe toxicity and HAART should be discontinued. However, the simple indexes (APRI, FIB-4, HGM-1 and HGM-2) are calculated in a relatively easy way using parameters easily available in routine clinical practice. Even though HA is a single molecule, its quantification is not commonly measured in hospitals, it cannot be obtained from normal clinical data, and it is more expensive.

While HA has been shown to be accurate when used in combination with other parameters in $\mathrm{HIV} / \mathrm{HCV}$ coinfected patients (SHASTA index [24], HGM-3 [22]), its effectiveness at assessing liver fibrosis as an isolated marker is poorer. For instance, according to data published by our group very recently [22], the AUROC of HGM-3, a combination which includes HA, was 0.939 for $\mathrm{F} \geq 3$, whereas the corresponding figure for HA alone reported here was 0.772 . However, others authors have reported AUC-ROC values for Hepascore, Fibrometer and SHASTA (three indexes which include HA), and Fibrotest [30] similar to AUC-ROC values of HA in our patients.

Moreover, we used a commercial HA-ELISA test (Echelon Biosciences) different from the enzyme-linked protein binding assay (Hyaluronic Acid Test Kit, Corgenix, Westminster, CO, USA) or the sandwich enzyme binding assay kit (Pharmacia, Uppsala, Sweden) used by others authors [23,25,37-41]. To the best of our knowledge, this test has not previously been reported as a fibrosis test. So, this paper is a validation study of the HA-ELISA test (Echelon Biosciences) although the HA levels in this study are quite different (about 10 times larger) from those previously reported in HCV or HIV/ HCV patients [23,25,38-41].

Aside from these laboratory biomarkers, liver fibrosis is evaluated using transient elastography (FibroScan) [42]. Our group reported an excellent diagnostic performance of liver stiffness for fibrosis and cirrhosis in HIV/ HCV-coinfected patients [43], which was higher than the diagnostic performance of HA shown here.

The diagnostic performance analysis in our cohort had several limitations: a) the low number of patients; b) this study was made on patients with well preserved immune function and the extrapolation to individuals with more marked immune suppression would require further study; c) we did not directly compare HA with SHASTA, Fibrotest, Hepascore or Fibrometer because we did not have all the clinical routine variables needed 
to calculate these indexes the day the liver biopsy was undertaken, and as a result of the use of the HA-ELISA test (Echelon Biosciences) the values of these combining scores would be quite different from those previously reported; d) we could not give exact information regarding biopsy length or portal tracts, but we found that only $1.68 \%$ of biopsies were defective for pathological diagnosis, and these cases were excluded from this study; e) only one pathologist read the biopsies and the biopsies were not validated by someone else; $f$ ) the uneven distribution of the stages of fibrosis in our cohort with a high proportion of absent to mild fibrosis and a low proportion of cirrhosis (11\%). However, we carried out an analysis using the DANA method, which is used when the distribution of fibrosis stages are highly asymmetric [44], and we did not find a significant increase in AUC-ROC values (data not shown).

\section{Conclusion}

The diagnostic accuracy of serum HA levels increases gradually with the hepatic fibrosis stage. However, HA is better than other simple non-invasive indexes using parameters easily available in routine clinical practice only for the diagnosing of cirrhosis.

\footnotetext{
Abbreviations

AUC-ROCS: Area under these ROC curves; $C H C$ : Chronic hepatitis C; F $\geq 2$ : Significant fibrosis; F $\geq 3$ : Advanced fibrosis; F4: Cirrhosis; HA: Hyaluronic acid; HAART: Highly active antiretroviral therapy; HCV: Hepatitis C virus; HIV: Human immunodeficiency virus; NPV: Negative predictive value; PPV: Positive predictive value; SE: Sensitivity; SP: Specificity; LR: Likelihood ratio; DOR: Diagnostic odds ratio; TP: True positive cases (correct diagnosis); TN: True negative cases (correct diagnosis); FP: False positive cases (over-diagnosis); FN: False negative cases (missed cases).
}

\section{Acknowledgements}

The authors thank Nick Weber for writing assistance during the preparation of the manuscript

Sources of financial support: This work was supported by grants from Instituto de Salud Carlos III (Ref. PI052411; Ref. PI07/90201, Ref. UIPY 1467/07) and Fundación para la Investigación y la Prevención del SIDA en España (FIPSE) (Ref. 36650/07) to SR. And from Fondo de Investigación Sanitaria (FIS) (Ref. ISCIII-RETIC RD06/006; Ref. PI080928) and FIPSE (Ref. 36443/03; Ref. $36702 / 07)$ to JB. Fundación para la Investigación y la Prevención del SIDA en España (FIPSE 24534/05, 24632/07), Fondo de Investigación Sanitaria (FIS) of Ministerio de Ciencia e Innovación FIS (PI052476, PI061479); Red RIS RD060006-0035; Fundación Caja Navarra, Comunidad de Madrid (S-SAL-01592006) and Task Force in Europe for Drug Development for the Young (TEDDY) to MAMF.

\section{Meetings at which parts of the data were presented:}

Resino S, Miralles P, Micheloud D, Bellón JM, Vargas A, Catalán P, Álvarez E, Cosín J, Lorente R, Sánchez-Conde M, Muñoz-Fernández MA, and Berenguer J. Diagnostic Accuracy of Serum Hyaluronic Acid for Advanced Fibrosis/ Cirrhosis in Patients Coinfected with HIV and HCV. $48^{\text {th }}$ Annual International Conference on Antimicrobial Agents and Chemotherapy (ICAAC)/Infectious. Diseases Society of America (IDSA) 46th Annual Meeting. Washington, DC, USA. October 25-28, 2008.

\section{Author details}

${ }^{1}$ Laboratory of Molecular Epidemiology of Infectious Diseases, National Centre of Microbiology, Instituto de Salud Carlos III, Majadahonda, Madrid, Spain. ${ }^{2}$ Biomedical Research Foundation, Hospital General Universitario
"Gregorio Marañón", Madrid, Spain. ${ }^{3}$ Agency for Health Technology Assessment, Instituto de Salud Carlos III, Madrid, Spain. ${ }^{4}$ Internal Medicine Department, Hospital General Universitario "Gregorio Marañón", Madrid, Spain. ${ }^{5}$ Infectious Diseases-HIV Unit, Hospital General Universitario "Gregorio Marañón", Madrid, Spain. 'Microbiology Department, Hospital General Universitario "Gregorio Marañón", Madrid, Spain. 7Pathology Department, Hospital General Universitario "Gregorio Marañón", Madrid, Spain. ${ }^{8}$ Molecular Immunobiology Laboratory, Hospital General Universitario "Gregorio Marañón", Madrid, Spain.

\section{Authors' contributions}

SR had primary responsibility for protocol development, participated in the design of the study performed the statistical analysis, and contributed to the writing of the manuscript. JMB, CA and AV participated in the design of the study, performed the statistical analysis, and contributed to the writing of the manuscript. RL carried out the immunoassays. EA had primary responsibility of fibrosis liver diagnosis. MMF, PM, PC, JCL, JC, and DM carried out patient screening, collecting and recording data, and contributed to the writing of the manuscript. JB conceived of the study, and participated in its design and coordination. All authors read and approved the final manuscript.

\section{Competing interests}

The authors declare that they have no competing interests.

Received: 5 March 2010 Accepted: 19 August 2010

Published: 19 August 2010

\section{References}

1. Graham CS, Baden LR, Yu E, Mrus JM, Carnie J, Heeren T, Koziel MJ: Influence of human immunodeficiency virus infection on the course of hepatitis C virus infection: a meta-analysis. Clin Infect Dis 2001, 33(4):562-569.

2. Soto B, Sanchez-Quijano A, Rodrigo L, del Olmo JA, Garcia-Bengoechea M, Hernandez-Quero J, Rey C, Abad MA, Rodriguez M, Sales Gilabert M, Gonzalez F, Miron P, Caruz A, Relimpio F, Torronteras R, Leal M, Lissen E: Human immunodeficiency virus infection modifies the natural history of chronic parenterally-acquired hepatitis $C$ with an unusually rapid progression to cirrhosis. J Hepatol 1997, 26(1):1-5.

3. Bica I, McGovern B, Dhar R, Stone D, McGowan K, Scheib R, Snydman DR: Increasing mortality due to end-stage liver disease in patients with human immunodeficiency virus infection. Clin Infect Dis 2001, 32(3):492-497.

4. Cacoub P, Geffray L, Rosenthal E, Perronne C, Veyssier P, Raguin G: Mortality among human immunodeficiency virus-infected patients with cirrhosis or hepatocellular carcinoma due to hepatitis $C$ virus in French Departments of Internal Medicine/Infectious Diseases, in 1995 and 1997. Clin Infect Dis 2001, 32(8):1207-1214.

5. Dienstag JL: The role of liver biopsy in chronic hepatitis C. Hepatology 2002, 36(5 Suppl 1):S152-160.

6. Manning DS, Afdhal NH: Diagnosis and quantitation of fibrosis. Gastroenterology 2008, 134(6):1670-1681.

7. Guechot J, Loria A, Serfaty L, Giral P, Giboudeau J, Poupon R: Serum hyaluronan as a marker of liver fibrosis in chronic viral hepatitis C: effect of alpha-interferon therapy. J Hepatol 1995, 22(1):22-26.

8. Guechot J, Laudat A, Loria A, Serfaty L, Poupon R, Giboudeau J: Diagnostic accuracy of hyaluronan and type III procollagen amino-terminal peptide serum assays as markers of liver fibrosis in chronic viral hepatitis $C$ evaluated by ROC curve analysis. Clin Chem 1996, 42(4):558-563.

9. Parise ER, Oliveira AC, Figueiredo-Mendes C, Lanzoni V, Martins J, Nader H, Ferraz ML: Noninvasive serum markers in the diagnosis of structural liver damage in chronic hepatitis C virus infection. Liver Int 2006, 26(9):1095-1099.

10. Saitou Y, Shiraki K, Yamanaka Y, Yamaguchi Y, Kawakita T, Yamamoto N, Sugimoto K, Murata K, Nakano T: Noninvasive estimation of liver fibrosis and response to interferon therapy by a serum fibrogenesis marker, YKL-40, in patients with HCV-associated liver disease. World J Gastroenterol 2005, 11(4):476-481.

11. Forns X, Ampurdanes S, Llovet JM, Aponte J, Quinto L, Martinez-Bauer E, Bruguera M, Sanchez-Tapias JM, Rodes J: Identification of chronic hepatitis 
C patients without hepatic fibrosis by a simple predictive model. Hepatology 2002, 36(4 Pt 1):986-992.

12. Wai $C T$, Greenson JK, Fontana RJ, Kalbfleisch JD, Marrero JA, Conjeevaram HS, Lok AS: A simple noninvasive index can predict both significant fibrosis and cirrhosis in patients with chronic hepatitis $C$. Hepatology 2003, 38(2):518-526.

13. Sterling RK, Lissen E, Clumeck N, Sola R, Correa MC, Montaner J, M SS, Torriani FJ, Dieterich DT, Thomas DL, Messinger D, Nelson M: Development of a simple noninvasive index to predict significant fibrosis in patients with HIV/HCV coinfection. Hepatology 2006, 43(6):1317-1325

14. Berenguer J, Bellon JM, Miralles P, Alvarez E, Sanchez-Conde M, Cosin J, Lopez JC, Alvarez F, Catalan P, Resino S: Identification of liver fibrosis in HIV/HCV-coinfected patients using a simple predictive model based on routine laboratory data. J Viral Hepat 2007, 14(12):859-869.

15. Jacobs WH, Goldberg SB: Statement on outpatient percutaneous liver biopsy. Dig Dis Sci 1989, 34(3):322-323.

16. Bedossa P, Poynard T: An algorithm for the grading of activity in chronic hepatitis C. The METAVIR Cooperative Study Group. Hepatology 1996, 24(2):289-293.

17. DeLong ER, DeLong DM, Clarke-Pearson DL: Comparing the areas under two or more correlated receiver operating characteristic curves: a nonparametric approach. Biometrics 1988, 44(3):837-845.

18. Song HH: Analysis of correlated ROC areas in diagnostic testing. Biometrics 1997, 53(1):370-382.

19. Glas AS, Lijmer JG, Prins MH, Bonsel GJ, Bossuyt PM: The diagnostic odds ratio: a single indicator of test performance. J Clin Epidemiol 2003, 56(11):1129-1135.

20. Afdhal NH, Nunes D: Evaluation of liver fibrosis: a concise review. Am J Gastroenterol 2004, 99(6):1160-1174

21. Poynard T, Munteanu M, Imbert-Bismut F, Charlotte F, Thabut D, Le Calvez S, Messous D, Thibault V, Benhamou Y, Moussalli J, Ratziu V: Prospective analysis of discordant results between biochemical markers and biopsy in patients with chronic hepatitis C. Clin Chem 2004, 50(8):1344-1355.

22. Resino S, Micheloud D, Miralles P, Bellon JM, Vargas A, Catalan P, Alvarez E, Cosin J, Lorente R, Lopez JC, Munoz-Fernandez MA, Berenguer J: Diagnosis of advanced fibrosis in HIV and hepatitis $C$ virus-coinfected patients via a new noninvasive index: the HGM-3 index. HIV Med 2010, 11(1):64-73.

23. Larrousse M, Laguno M, Segarra M, De Lazzari E, Martinez E, Blanco JL, Leon A, Deulofeu R, Miquel R, Milinkovic A, Lonca M, Miro JM, Biglia A, Murillas J, Gatell JM, Mallolas J: Noninvasive diagnosis of hepatic fibrosis in HIV/HCV-coinfected patients. J Acquir Immune Defic Syndr 2007, 46(3):304-311.

24. Kelleher TB, Mehta SH, Bhaskar R, Sulkowski M, Astemborski J, Thomas DL, Moore RE, Afdhal NH: Prediction of hepatic fibrosis in HIV/HCV coinfected patients using serum fibrosis markers: the SHASTA index. $J$ Hepatol 2005, 43(1):78-84.

25. Nunes $D$, Fleming $C$, Offner $G$, O'Brien $M$, Tumilty $S$, Fix O, Heeren $T$, Koziel M, Graham C, Craven DE, Stuver S, Horsburgh CR: HIV infection does not affect the performance of noninvasive markers of fibrosis for the diagnosis of hepatitis C virus-related liver disease. J Acquir Immune Defic Syndr 2005, 40(5):538-544.

26. Trang T, Petersen JR, Snyder N: Non-invasive markers of hepatic fibrosis in patients co-infected with HCV and HIV: comparison of the APRI and FIB4 index. Clin Chim Acta 2008, 397(1-2):51-54.

27. Macias J, Giron-Gonzalez JA, Gonzalez-Serrano M, Merino D, Cano P, Mira JA, Arizcorreta-Yarza A, Ruiz-Morales J, Lomas-Cabeza JM, GarciaGarcia JA, Corzo JE, Pineda JA: Prediction of liver fibrosis in human immunodeficiency virus/hepatitis $C$ virus coinfected patients by simple non-invasive indexes. Gut 2006, 55(3):409-414.

28. Loko MA, Castera L, Dabis F, Le Bail B, Winnock M, Coureau G, BioulacSage P, de Ledinghen V, Neau D: Validation and comparison of simple noninvasive indexes for predicting liver fibrosis in HIV-HCV-coinfected patients: ANRS CO3 Aquitaine cohort. Am J Gastroenterol 2008, 103(8):1973-1980.

29. Tural C, Tor J, Sanvisens A, Perez-Alvarez N, Martinez E, Ojanguren I, GarciaSamaniego JA, Rockstroh J, Barluenga E, Muga R, Planas R, Sirera G, ReyJoly C, Clotet B: Accuracy of Simple Biochemical Tests in Identifying Liver Fibrosis in Patients Co-Infected With Human Immunodeficiency Virus and Hepatitis C Virus. Clin Gastroenterol Hepatol 2008, 7(1):339-345.
30. Cacoub P, Carrat F, Bedossa P, Lambert J, Penaranda G, Perronne C, Pol S, Halfon P: Comparison of non-invasive liver fibrosis biomarkers in HIV/ HCV co-infected patients: the fibrovic study-ANRS HC02. J Hepatol 2008, 48(5):765-773.

31. Cales $P$, de Ledinghen V, Halfon P, Bacq Y, Leroy V, Boursier J, Foucher J, Bourliere M, de Muret A, Sturm N, Hunault G, Oberti F: Evaluating the accuracy and increasing the reliable diagnosis rate of blood tests for liver fibrosis in chronic hepatitis C. Liver Int 2008, 28(10):1352-1362.

32. Kontorinis N, Dieterich D: Hepatotoxicity of antiretroviral therapy. AIDS Rev 2003, 5(1):36-43.

33. Bonacini $\mathrm{M}$ : Liver injury during highly active antiretroviral therapy: the effect of hepatitis C coinfection. Clin Infect Dis 2004, 38(Suppl 2):S104-108.

34. Cole JL, Marzec UM, Gunthel CJ, Karpatkin S, Worford L, Sundell IB, Lennox JL, Nichol JL, Harker LA: Ineffective platelet production in thrombocytopenic human immunodeficiency virus-infected patients. Blood 1998, 91(9):3239-3246.

35. Mallewa JE, Wilkins E, Vilar J, Mallewa M, Doran D, Back D, Pirmohamed M HIV-associated lipodystrophy: a review of underlying mechanisms and therapeutic options. J Antimicrob Chemother 2008, 62(4):648-660.

36. Samaras $\mathrm{K}$ : Metabolic consequences and therapeutic options in highly active antiretroviral therapy in human immunodeficiency virus-1 infection. J Antimicrob Chemother 2008, 61(2):238-245.

37. Mehta P, Ploutz-Snyder R, Nandi J, Rawlins SR, Sanderson SO, Levine RA: Diagnostic accuracy of serum hyaluronic acid, FIBROSpect II, and YKL-40 for discriminating fibrosis stages in chronic hepatitis C. Am J Gastroenterol 2008, 103(4):928-936.

38. Poynard T, Imbert-Bismut F, Ratziu V, Chevret S, Jardel C, Moussalli J, Messous D, Degos F: Biochemical markers of liver fibrosis in patients infected by hepatitis $C$ virus: longitudinal validation in a randomized trial. J Viral Hepat 2002, 9(2):128-133.

39. Leroy V, Monier F, Bottari S, Trocme C, Sturm N, Hilleret MN, Morel F, Zarski JP: Circulating matrix metalloproteinases 1, 2, 9 and their inhibitors TIMP-1 and TIMP-2 as serum markers of liver fibrosis in patients with chronic hepatitis C: comparison with PIIINP and hyaluronic acid. Am J Gastroenterol 2004, 99(2):271-279.

40. Sene D, Limal N, Messous D, Ghillani-Dalbin P, Charlotte F, Thiolliere JM, Piette JC, Imbert-Bismut F, Halfon P, Poynard T, Cacoub P: Biological markers of liver fibrosis and activity as non-invasive alternatives to liver biopsy in patients with chronic hepatitis $C$ and associated mixed cryoglobulinemia vasculitis. Clin Biochem 2006, 39(7):715-721.

41. Halfon P, Bourliere M, Penaranda G, Deydier R, Renou C, Botta-Fridlund D, Tran A, Portal I, Allemand I, Rosenthal-Allieri A, Ouzan D: Accuracy of hyaluronic acid level for predicting liver fibrosis stages in patients with hepatitis C virus. Comp Hepatol 2005, 4:6.

42. Moreno S, Garcia-Samaniego J, Moreno A, Ortega E, Pineda JA, del Romero J, Tural C, von Wichmann MA, Berenguer J, Castro A, Espacio R: Noninvasive diagnosis of liver fibrosis in patients with HIV infection and HCV/HBV co-infection. J Viral Hepat 2009, 16(4):249-258.

43. Sanchez-Conde M, Montes-Ramirez ML, Miralles P, Castro Alvarez JM, Bellon JM, Ramirez M, Arribas JR, Gutierrez I, Lopez JC, Cosin J, Alvarez E, Gonzalez J, Berenguer J: Comparison of transient elastography and liver biopsy for the assessment of liver fibrosis in HIV/hepatitis $C$ viruscoinfected patients and correlation with noninvasive serum markers. J Viral Hepat 2010, 17(4):280-6.

44. Poynard T, Halfon P, Castera L, Munteanu M, Imbert-Bismut F, Ratziu V, Benhamou Y, Bourliere M, de Ledinghen V: Standardization of ROC curve areas for diagnostic evaluation of liver fibrosis markers based on prevalences of fibrosis stages. Clin Chem 2007, 53(9):1615-1622.

\section{Pre-publication history}

The pre-publication history for this paper can be accessed here: http://www.biomedcentral.com/1471-2334/10/244/prepub

\section{doi:10.1186/1471-2334-10-244}

Cite this article as: Resino et al:: Can serum hyaluronic acid replace simple non-invasive indexes to predict liver fibrosis in HIV/Hepatitis C coinfected patients?. BMC Infectious Diseases 2010 10:244. 